Marcin Kosman

\title{
„TRAMWAJ ZWANY POŻĄDANIEM” WEDEUG JACKA PONIEDZIAŁKA
}

\author{
"A streetcar named desire" and its translation into Polish \\ by Jacek Poniedziałek
}

\begin{abstract}
Indubitably, Tennessee Williams is one of the most influential playwrights of the $20^{\text {th }}$ century. Despite his grand popularity only two plays had been translated before Jacek Poniedziałek published his collection. The aim of the paper is to show the translation strategies implemented by the translator and comment on the validity of his choices. In contrast to Kazimierz Piotrowski and Eugeniusz Cęcalski, Poniedziałek preserves vernacular language and often adds words or phrases that could not have been uttered in the forties. This provokes a question what kind of language is spoken in Poniedziałek's Streetcar. In my research I try to find these elements of the play which might have been lost in the sphere of drama translation. Moreover, I will compare Poniedzialek's strategy with a more conservative approach taken by the previous translator.

Key words: culture bound items, drama translation, Jacek Poniedziałek, stageability, sociology of translation, Tennessee Williams

Słowa kluczowe: elementy kulturowe w przekładzie, przekład tekstu dramatycznego, Jacek Poniedziałek, sceniczność, socjologia przekładu, Tennessee Williams
\end{abstract}

Sztuki Tennessee Williamsa, jednego z najbardziej rozpoznawalnych dramaturgów amerykańskich XX wieku, cieszą się popularnością również w Polsce. Takie pozycje, jak Noc Iguany, Tatuowana róża czy Nagle, zeszłego lata były wielokrotne wystawiane na deskach polskich teatrów. Mimo niekwestionowanej popularności sztuki Williamsa zostały wydane w oficjalnej formie książkowej jedynie dwukrotnie: Tramwaj zwany pożądaniem w tłumaczeniu Eugeniusza Cękalskiego opublikowany w „Dialogu” w roku 1957; dziesięć lat później Kazimierz Piotrowski przełożył Szklaną menażerię, która znalazła się w trzecim tomie antologii Współczesny dramat amerykański. Oczywiście dzieła Williamsa były tłumaczone i interpretowane jeszcze wielokrotnie, lecz poza wspomnianymi przekładami żadna wersja nie została oficjalnie wydana. W 2012 r. nakładem Wydawnictwa Znak ukazał się zbiór dramatów Williamsa w przekładzie Jacka Poniedziałka Tramwaj zwany po$\dot{z} a ̨$ daniem $i$ inne dramaty, w którym oprócz tytułowej sztuki znalazła się Szklana 
menażeria, Kotka na goracym blaszanym dachu, Stodki ptak młodości i Noc Iguany. Tym samym polskie tłumaczenia trzech ostatnich pozycji oficjalnie wydano po raz pierwszy. W swojej pracy odnoszę się jednak wyłącznie do Tramwaju..., który porównuję z pierwszym tłumaczeniem autorstwa Eugeniusza Cękalskiego. Williams, jako autor głęboko zakorzeniony w tradycji amerykańskiego Południa, pisał w dużej mierze o problemach egzystencjalnych ludzi tamtych czasów. Dekadencki klimat Stanów Zjednoczonych lat 40. uchodzi za specyficzny dla określonego społeczeństwa, przez co tłumacz, próbując oddać pełne wątki w języku kultury docelowej, może napotkać pewne trudności. Warto zwrócić choćby uwagę na fakt, iż nazwa gatunku, do którego przedstawicieli zalicza się samego Williamsa - southern gothic - w polskich przekładach nie jest tłumaczo$\mathrm{na}^{1}$. Z drugiej strony Williams prezentuje treści często uznawane za uniwersalne, nawet jeśli język czy środowisko bohaterów jego sztuk są w istocie hermetyczne². W związku z tym analiza przekładu Poniedziałka to również próba odpowiedzi na pytanie, jak tłumacz poradził sobie ze specyficznym klimatem Williamsa i jak udało mu się go przenieść na polski grunt.

Należy zauważyć, że obaj tłumacze sztuk Williamsa - i Cękalski, i Poniedziałek - nie posiadali wykształcenia filologicznego. Zaliczali się do ludzi sztuki i byli związani z kinem i teatrem. Cękalski głównie jako reżyser filmowy i teoretyk kina; Poniedziałek znany jest przede wszystkim ze swojej działalności aktorskiej, jednak w ostatnich latach dał się również poznać jako reżyser i scenarzysta teatralny. Może to zatem sugerować, że Poniedziałek będzie starał się - prawdopodobnie kosztem poprawności filologicznej - wydobyć, idąc za Sophią Totzevą, potencjał teatralny (ang. theatrical potential) sztuki. Agnieszka Romanowska, definiując pojęcie wprowadzone przez bułgarską tłumaczkę, pisze, iż rzeczony potencjał opiera się na „potencjalnych sposobach zaistnienia tekstu w wielowymiarowym systemie znaków" ${ }^{3}$. System ten rozumiany jest jako przedstawienie. Totzeva sądzi, iż dramaty operują na wielu płaszczyznach, przez co przekład sztuki jest $w$ istocie przekładem intersemiotycznym, gdyż należy w nim uwzględnić elementy lingwistyczne z różnych kodów językowych ${ }^{4}$. Tramwaj zwany pożądaniem Poniedziałka różni się od tłumaczenia Cękalskiego

1 A. Zatora, Użycie konwencji. Instrumentarium grozy i jego misja $w$ „Ciemno, prawie noc” Joanny Bator, „Acta Humana” 2015, t. 6 (1), s. 214.

2 M. Subashi, E. Ostrosi Veliaj, Tennessee Williams's Dramatic World, „European Journal of Language and Literature Studies” 2015, vol. 1, no. 3, s. 78.

3 A. Romanowska, „Hamlet” po polsku. Teatralność szekspirowskiego tekstu dramatycznego jako zagadnienie przekładoznawcze, Księgarnia Akademicka, Kraków 2005, s. 10 .

4 S. Totzeva, Realizing Theatrical Potential: The Dramatic Text in Performance and Translation, [w:] The Practices of Literary Translation. Constraints and Creativity, red. J. Boase-Beier, M. Holman, St. Jerome Publishing, Manchester 1999, s. 82. 
na wielu płaszczyznach. Pierwszą z fundamentalnych różnic jest dystans między bohaterami i stopień sformalizowania dyskursu. W pierwszym akcie, gdy Eunice po raz pierwszy spotyka zagubioną Blanche, między bohaterkami nawiązuje się następujący dialog:

Eunice [finally]: What's the matter, honey? Are you lost?

Blanche [with faintly hysterical humor]: They told me to take a streetcar named Desire, and then transfer to one called Cemeteries and ride six blocks and get off at Elysian Fields! ${ }^{5}$

Pytania Eunice w wersji Cękalskiego brzmią: „O co chodzi, paniusiu? Zgubiła pani coś", podczas gdy Poniedziałek optuje za bardziej bezpośrednim rozwiązaniem: „Co jest, kochanie? Zgubiłaś się?”7. Forma „paniusiu” oczywiście może być uznana za nacechowaną negatywnie, ale następująca po niej „pani” przedstawia Eunice jako osobę, która chce być miła i uprzejma, ale ze względu na brak kulturalnego obycia i etykiety nie wychodzi jej to zbyt dobrze; u Poniedziałka zamysł Williamsa zdaje się oddany nieco rzetelniej, bowiem bohaterowie sztuki są bezpośredni i nie ma między nimi dystansu, który jest charakterystyczny dla Blanche. Angielskie you nie określa jednoznacznie stopnia sformalizowania wypowiedzi, gdyż może być odczytane w języku polskim zarówno w drugiej, jak i w trzeciej osobie liczby pojedynczej. Biorąc jednak pod uwagę obecne w oryginale kolokwializmy, regionalizmy i język nacechowany emocjonalnie, interpretacja Poniedziałka jawi się jako naturalna i bardziej zasadna. W kwestii form zwracania się bohaterów do siebie Poniedziałek jest konsekwentny, bowiem Blanche jest jedyną postacią zwracającą się do tutejszych per „pan” lub „pani”. W dalszym fragmencie tej sceny pytanie Eunice Uh, huh, I think so. So you're Stella's sister? zostało przetłumaczone jako „No mówię ci. Więc jesteś siostrą Stelli?”; odpowiedź Blanche brzmi „Dziękuję, że mnie pani wpuściła” (ang. Thanks for letting me in), dzięki czemu widać różnicę w sposobie mówienia postaci. Fakt, że Blanche DuBois mówi i rozumuje w inny sposób od mieszkańców Nowego Orleanu ma niebagatelne znaczenie w kontekście wymowy całości utworu. Odmienność Blanche zostaje zasygnalizowana nie tylko przez użycie trzeciej osoby liczby pojedynczej.

5 T. Williams, A Streetcar Named Desire, The New American Library, New York 1974, s. 15.

6 T. Williams, Tramwaj zwany pożądaniem, przeł. E. Cękalski, „Dialog: miesięcznik Związku Literatów Polskich” 1957, t. 2, nr 6, s. 52.

7 T. Williams, Tramwaj zwany pożądaniem i inne dramaty, przeł. J. Poniedziałek, Wydawnictwo Znak, Kraków 2012, s. 74.

8 Ibidem, s. 75.

9 Ibidem. 
Poprawność językowa tej bohaterki również jest kwestią, na którą Poniedziałek zwraca uwagę. Blanche, jako nauczycielka języka angielskiego, jest jedyną postacią w sztuce, która w swoich wypowiedziach posługuje się formami poprawnymi gramatycznie. Przykładowo zaimek „tę” pojawia się wyłącznie w kwestiach przypisanych Blanche, np. „Na stratę... na tę stratę"10. Zabieg ten wydaje się w pełni zamierzony, bowiem pozostali bohaterowie konsekwentnie posługują się formą uważaną za niezalecaną, mówiąc „tą” w bierniku liczby pojedynczej zamiast w narzędniku: „Widziałaś tą kręgielnię za rogiem?”"; „Poczekam, aż skończy tą swoją relaksującą kąpiel” ${ }^{2}$. Można jednak zaobserwować u tłumacza pewną niekonsekwencję, gdyż zdanie „Gdzie idziesz?”"13 wypowiedziane przez Blanche jest formą charakterystyczną dla języka potocznego, co kłóci się z poprzednią strategią Poniedziałka, jednakże wygląda to jedynie na pojedyncze przeoczenie.

W kontraście z poprawną i egzaltowaną Blanche stoją pozostali bohaterowie sztuki, na czele ze Stanleyem Kowalskim. Wypowiedzi Stanleya w polskim tłumaczeniu są jednak bardziej dosadne niż u Tennessee Williamsa.

Tabela 1. Porównanie wulgarności

\begin{tabular}{|l|l|}
\hline \multicolumn{1}{|c|}{ Tennessee Williams } & \multicolumn{1}{c|}{ Jacek Poniedziałek } \\
\hline Roughouse & Napierdalanka \\
\hline I am cursing your rotten luck & Miałeś, kurwa, szczęście \\
\hline $\begin{array}{l}\text { Lie Number One: All this sqeuamishes she } \\
\text { puts on! }\end{array}$ & $\begin{array}{l}\text { Bajeczka Numer Jeden: jej } \\
\text { świętojebliwość!). }\end{array}$ \\
\hline Let the rut go of me, you sons of bitches! & Spadówa, chuje, skurwysyny! \\
\hline $\begin{array}{l}\text { The four-letter word deprived us of our } \\
\text { plantation }\end{array}$ & $\begin{array}{l}\text { Pogoń za dupą ograbiła nas z naszej } \\
\text { plantacji }\end{array}$ \\
\hline I mean it's a damned good thing & Bo to jest kurewsko dobra rzecz \\
\hline
\end{tabular}

Tam, gdzie w oryginale występują potocyzmy czy kolokwializmy, Poniedziałek wprowadza przekleństwa. Nawet w sytuacjach, w których przekleństwa pojawiają się i u Williamsa, Poniedziałek je mnoży, sprawiając, że wypowiedź danej postaci staje się jeszcze bardziej wulgarna, konsekwentnie obniżając rejestr. Kowalski nie jest jedyną postacią, w języku której przekleństwa zostają mocniej wyeksponowane; takie formy pojawiają się również u Blanche, mimo że Williams stara się je nieco tonować (por. dwa ostatnie przykłady w tabeli powyżej).

\footnotetext{
10 Ibidem, s. 82.

11 Ibidem, s. 75.

12 Ibidem, s. 85.

13 Ibidem, s. 81.
} 
Dosadność języka i jednoznaczność przekazu wydają się swoistym leitmotivem tłumaczenia Poniedziałka. Teatrolodzy często podkreślają rolę seksualności i przemocy w twórczości Williamsa, ale równocześnie często wyrażona jest ona w formie nie wprost, poprzez m.in. dwuznaczność dialogó $w^{14}$. Jacek Poniedziałek z tej dwuznaczności rezygnuje, czyniąc swój przekaz bardziej konkretnym i dobitnym. Przykładem tej strategii jest jedna z pierwszych rozmów Stanleya i Blanche:

Stanley: Do you mind if I make myself comfortable? Be comfortable is my motto.

Stanley: Nie przeszkadza ci, jak sobie zrobię dobrze? Robić sobie dobrze to moje motto ${ }^{15}$.

Kojarzące się jednoznacznie polskiemu czytelnikowi „robić sobie dobrze” jasno implikuje aluzję do seksu. Podobny zabieg znajdziemy w wymianie zdań sióstr DuBois w scenie szóstej, kiedy Blanche i Stella dyskutują o walorach Stanleya:

Stella: Nie chodzi o czoło ani o geniusza.

Blanche: Więc co to jest i gdzie się to znajduje? Ciekawa jestem.

Stella: W majtkach ${ }^{16}$.

U Williamsa odpowiedzią Stelli na pytanie siostry jest It's a drive that he has. Angielskie drive może być tłumaczone jako popęd (najczęściej w kontekście psychologicznym, np. primary drive jako popęd pierwotny w teorii freudowskiej), ale równie często funkcjonuje w znaczeniu „zapał”, „motywacja” czy „ambicja”. Ponownie mnogość interpretacyjna obecna w oryginale została w polskim tłumaczeniu zneutralizowana. Taki stan rzeczy można również zaobserwować $\mathrm{w}$ tłumaczeniu pojedynczych słów i zdań: degenerate - zboczeniec; when the devil is in you - kiedy nas cipka swędzi; I had many intimacies with strangers - To prawda - puszczałam się.

Odmienną kwestią jest tożsamość bohaterów Tramwaju... Jak zostało już wspomniane - postacie Tennessee Williamsa to Amerykanie lat 40. XX wieku, którzy są mocno osadzeni w klimacie swoich czasów i regionu, w którym żyją. Jacek Poniedziałek nie decyduje się na spolszczenie imion, co zdawałoby się strategią właściwą dla literatury dziecięcej ${ }^{17}$, ale w inny sposób stara się uczynić

14 G. C. Guilbert, Queering and Dequeering the Text. Tennessee Williams's A Streetcar Named Desire, „Cercles” 2004, no. 10, s. 90-91.

15 T. Williams, Tramwaj zwany pożądaniem i inne dramaty..., s. 82.

16 Ibidem, s. 93.

17 M. Borodo, Adaptacje w dobie globalizacji, „Przekładaniec” 2009, nr 22-23: Baśń w przekładzie, s. 206. 
amerykański kontekst czytelnym dla Polaka, co tym samym kieruje jego tłumaczenie w stronę domestykacji. Pisząc o udomowieniu, należy wspomnieć o elementach nacechowanych kulturowo, które Krzysztof Hejwowski definiuje „jako takie elementy tekstu, które w sposób szczególny łączą się z kulturą danego kraju [...] nazwy i zwroty związane z organizacją życia w kraju kultury wyjściowej, obyczajami i przyzwyczajeniami (takimi jak tradycje kulinarne), cytaty i aluzje mające ścisły związek z literaturą danego kraju, aluzje do historii i do innych sfer kultury, takich jak muzyka, film, malarstwo"18. Nie ulega wątpliwości, że czytelnik znajdzie u Williamsa wiele elementów, które są papierkiem lakmusowym amerykańskiej kultury sprzed kilku dekad. Wybrane elementy kulturowe w interpretacji Poniedziałka zostały przedstawione w formie tabeli.

Tabela 2. Tłumaczenie elementów kulturowych

\begin{tabular}{|l|l|}
\hline \multicolumn{1}{|c|}{ Tennessee Williams } & \multicolumn{1}{c|}{ Jacek Poniedziałek } \\
\hline A poor boy's sandwich & Kebab \\
\hline $\begin{array}{l}\text { A summer tea or cocktail party in the } \\
\text { garden district }\end{array}$ & Letnie garden albo cocktail party \\
\hline a coke's in the icebox & cola w lodówce \\
\hline you bring the beer! & ty przynosisz browara! \\
\hline Jax beer! & Pilznera! \\
\hline $\begin{array}{l}\text { Why don't somebody go to the Chinaman's } \\
\text { and bring a load of chop suey? }\end{array}$ & Skoczy ktoś do chinola po chop sueya? \\
\hline $\begin{array}{l}\text { She appreciated your sending over that } \\
\text { custard }\end{array}$ & $\begin{array}{l}\text { Zrobiłaś jej dużą niespodziankę tym } \\
\text { ciastem }\end{array}$ \\
\hline Chocolate? Cherry? & Fanty? Wiśniówki? \\
\hline a box of aspirin tablets & z całym pudełkiem relanium \\
\hline I went out with him at college & Chodziłam z nim w college’u \\
\hline
\end{tabular}

W niektórych miejscach Poniedziałek decyduje się na bardziej ogólną i opisową metodę tłumaczenia. Tak jest choćby przy custard - potrawie popularnej w krajach anglojęzycznych, ale stosunkowo mało znanej w Polsce, dlatego tłumacz oddaje ją jako zwykłe „ciasto”. Inne formy pozostawione są w języku angielskim, zapewne przez wzgląd na brak dostatecznie rezonujących odpowiedników w kulturze docelowej oraz na przyjęcie w mowie polskiej (chop suey, garden party, cola, college). Wybrane elementy uległy swego rodzaju kolokwializacji, co również współgra z wcześniejszymi wyborami tłumacza (chinol, fanta, browar).

18 K. Hejwowski, Kognitywno-komunikacyjna teoria przekładu, Wydawnictwo Naukowe PWN, Warszawa 2004, s. 71-72. 
Z kolei decyzję o wprowadzeniu kebabu można uznać za kontrowersyjną; a poor boy's sandwich to kanapka po' boy, która jest jednym z flagowych dań serwowanych w Luizjanie - około trzydziestocentymetrowa bagietka z pieczoną wołowiną lub owocami morza. Kebab nie był daniem znanym w Ameryce Williamsa, lecz niewątpliwie jest specjałem znanym w XXI-wiecznej Polsce. Mimo tego Poniedziałek nie decyduje się na zastąpienie chop sueya sajgonkami lub inną potrawą charakterystyczną dla kuchni chińskiej. Dodatkowo, przy przetłumaczeniu tamales jako kiełbaski, u dołu strony pojawia się przypis, w którym Poniedziałek wyjaśnia, iż przywołany termin to „meksykańskie rolady z różnym nadzieniem”. Należy przy tym zaznaczyć, że jest to jeden z dwóch przypisów w całej sztuce. Drugi raz przypis objaśniający pojawia się przy okazji wspomnienia Mardi Gras w scenie dziesiątej. W zakresie tłumaczenia nazw tradycyjnych dań mamy zatem do czynienia z trzema różnymi strategiami, co pokazuje pewną niekonsekwencję tłumacza, który operuje różnymi wyborami, stojąc przed tym samym zadaniem. Decyzja o posłużeniu się przypisem tym bardziej dziwi, gdyż sceniczność (ang. stageability) - ważny element teatralnego potencjału - zakłada, że odbiór sztuki odbywa się przede wszystkim na scenie, nie poprzez czytanie tekstu ${ }^{19}$. Biorąc pod uwagę specyficzny język bohaterów i ich dosadność, wydaje się zasadne, że jeżeli zamysłem Poniedziałka było wystawienie Tramwaju... na deskach teatru, to wprowadzenie przypisu wydaje się być zbędne.

Tłumaczenie poszczególnych elementów kulturowych prowokuje również pytanie o świeżość języka Poniedziałka. Zdaje się on stylizowany na współczesny, o czym świadczą nie tylko neutralizacje poszczególnych elementów kulturowych, ale także swoista hybrydyzacja dwóch języków, którą można określić jako Ponglish ${ }^{20}$.

Tabela 3. Przykłady kontaminacji dwóch języków

\begin{tabular}{|l|}
\hline Bo mnie wystawił mój lover? \\
\hline gramy w Gali albo na West Sajdzie \\
\hline Wyluzuj, men \\
\hline znała więcej przekleństw niż mister Kowalski \\
\hline Hej! Stella, darling \\
\hline
\end{tabular}

Jest to zabieg zamierzony, lecz w niektórych miejscach w sztuce pojawiają się konstrukcje gramatyczne, które są dosłownym tłumaczeniem słów Williamsa, przez co kwestie wypowiadane przez bohaterów nie brzmią naturalnie.

19 K. Windle, The Translation of Drama, [w:] The Oxford Handbook of Translation Studies, red. K. Malmkjær, K. Windle, Oxford University Press, Oxford 2011, s. 156.

${ }^{20}$ M. Błasiak-Tytuła, Ponglish jako przykład adaptacji językowo-kulturowej, „Annales Universitatis Paedagogicae Cracoviensis Studia de Cultura” 2013, t. 5, s. 109. 
Przykładowo w scenie drugiej oburzony na Blanche Stanley krzyczy: I don't want no ifs, ands or buts!, co Jacek Poniedziałek tłumaczy jako: „Nie chcę żadnych »chyba, może, ale! «"21. W języku polskim powiedzielibyśmy raczej „żadnych ale”, podczas gdy twór Poniedziałka jest kalką z języka angielskiego. Podobnie sprawa ma się ze zdaniem Now the buttons! I can't do nothing with them, które u Poniedziałka brzmi dość niezręcznie: „Nie kumam tych guzików ${ }^{22}$ ”. Przypomina ono angielską frazę don't get something, która, notabene, w sztuce nie występuje. „Kumanie guzików" brzmi w uszach polskiego odbiorcy obco i sztucznie. Paralelna sytuacja występuje w przypadku tłumaczenia zdania $A$ place like that must be awful hard to keep up - u Poniedziałka: „To musi być piekło utrzymać taki dom”23, co zdaje się być dosłownym przekładem frazy hard as hell.

Nie oznacza to jednak, że akcja sztuki rozgrywa się we współczesnej Warszawie. Tłumacz nie zmienił wstępu do sceny pierwszej, w której Williams nakreśla miejsce akcji (Pola Elizejskie w Nowym Orleanie). Wyjściowym językiem Tramwaju... wciąż jest angielski, o czym świadczy m.in. wypowiedź Stanleya ze sceny jedenastej, gdy poprawia hiszpańskojęzycznego Pabla, by mówił w normalnym języku: „Po angielsku, bambusie ${ }^{24 ”}$. Niektóre wybory leksykalne Poniedziałka zdają się jednak znacząco sugerować, że czytelnik niezupełnie ma do czynienia z Ameryką lat minionych. Oprócz wspomnianego wcześniej kebabu Poniedziałek wprowadza takie zwroty, jak: „alko”, „disco w remizie”, „słodkiego koziołka matołka”, „petro-dolar”, które funkcjonują wyłącznie w polskojęzycznym obszarze kulturowym, przy czym są jednocześnie charakterystyczne dla współczesnej mowy. Specyficzny język Williamsa Poniedziałek często oddaje również za pomocą regionalizmów z różnych stron Polski: „se”, „chono tu”, „nie ciąg tego”. Miejscami wydaje się, że tłumacz posunął się zbyt daleko w próbie uwspółcześnienia dialogów, w sztuce pojawiają się bowiem modyfikacje albo zupełnie nic nie mówiące polskiemu czytelnikowi sformułowania („W życiu Romana!”; „Bajery, buzery, numery!”; „Ecie-pecie, co mnie nazywa małpą z dżungli”), albo niegdyś modne wyrażenia, obecnie jednak przestarzałe i nie mające już takiego efektu, jak kiedyś („Jak jechały Szwedy!”; „I doszłaś do tej - odjechanej - brylantowej - korony?”).

$\mathrm{Z}$ drugiej strony nowoczesność miesza się z archaicznym już językiem. Poniedziałek nie zdecydował się na zupełne uwspółcześnienie świata Williamsa, dlatego Blanche zakłada na głowę tiarę, a swoje ubranie pakuje do kufra. Niektóre wyzwiska bardziej też pasują do konserwatywnej wersji Cękalskiego sprzed lat niż do wulgarnego i drapieżnego tłumaczenia Poniedziałka: „Ile mi napsuła krwi?”; „Ciszej tam, kury, skończcie już te wasze trele!”; „Ty, kanalio!”;

${ }^{21}$ T. Williams, Tramwaj zwany pożądaniem i inne dramaty..., s. 89.

22 Ibidem, s. 87.

23 Ibidem, s. 75.

24 Ibidem, s. 137. 
„Wpierw rzucę okiem!” - są to frazy, których raczej próżno szukać u pijących alko i posilających się kebabem bywalców imprez w remizie. Jacek Poniedziałek ponownie wykazuje się w swoim tłumaczeniu niekonsekwencją, stale mieszając rejestry i style.

Fakt, iż Tennessee Williams nie doczekał się w Polsce wielu przekładów, wpływa na analizę interpretacji Jacka Poniedziałka dwojako. Jako jedyny szeroko dostępny na rynku polskim przekład znajduje się on pod obserwacją czytelników, dzięki czemu prawdopodobieństwo wychwycenia ewentualnych błędów i niedociągnięć jest większe. $Z$ drugiej strony - jako pionier działający na nieodkrytym dotąd terenie - tłumacz stanął przed trudniejszym zadaniem. Poniedziałek, będąc czynnym aktorem i reżyserem, kierował się w swojej pracy translatologicznej w stronę sceniczności i grywalności (niem. Spielbarkeit), co jest zabiegiem coraz popularniejszym we współczesnej teatrologii ${ }^{25}$. Na trudności w odbiorze pracy Poniedziałka składa się swego rodzaju niekoherencja i niedokładność: na ogół bohaterowie mówią językiem prostym, kolokwialnym i dynamicznym; można jednak znaleźć wiele miejsc, w których pojawiają się archaizmy, konstrukcje obce dla języka polskiego lub też nieudane próby uwspółcześniania języka. Z filologicznego punktu widzenia przekład Poniedziałka pozostawia nieco do życzenia, głównie w odniesieniu do spójnego doboru strategii tłumaczeniowych: w Tramwaju zwanym pożądaniem domestykacja miesza się $\mathrm{z}$ egzotyzacją.

Nie ulega wątpliwości, że tłumaczenie Poniedziałka odbiega od oryginału Williamsa. Zmiany, które naniósł tłumacz, nie są jednak aż tak znaczące, żeby nowo powstały tekst można nazwać adaptacją. W gruncie rzeczy jest to ciekawy eksperyment stylistyczny, który wprawdzie miejscami pozostaje niespójny, ale całościowo dobrze oddaje ducha postaci Williamsa, o których Michał Lachman pisze, że są to „twarde jednostki rzucone na kolana, które nie potrafią przyznać się do poczucia straty, ale buntują się przeciw przemijaniu i nieodwracalnej utracie czegoś, co je stworzyło i uformowało" ${ }^{26}$. Mając to na uwadze, wydaje się zasadne stwierdzenie, że Poniedziałek tworzył swoje tłumaczenie głównie z myślą o wystawianiu Williamsa na scenie. Zważywszy na fakt, że sztuka wystawiana jest na deskach warszawskich do dziś, można dojść do konkluzji, że w ostatecznym rozrachunku Jacek Poniedziałek należycie wywiązał się ze swojego zadania translatologicznego.

25 S. Totzeva, Das theatrale Potential des dramatischen Textes. Ein Beitrag zur Theorie von Drama und Dramenübersetzung, Gunter Narr Verlag, Tübingen 1995, s. 282.

26 M. Lachman, Menażeria słowa, „Didaskalia” 2012, nr 112, s. 167. 


\section{Bibliografia}

Błasiak-Tytuła M., Ponglish jako przykład adaptacji językowo-kulturowej, „Annales Universitatis Paedagogicae Cracoviensis Studia de Cultura” 2013, t. 5, s. 106-112.

Borodo M., Adaptacje w dobie globalizacji, „Przekładaniec” 2009, nr 22-23: Baśń w przekładzie, s. 205-219.

Guilbert G. C., Queering and Dequeering the Text. Tennessee Williams's A Streetcar Named Desire, „Cercles” 2004, no. 10, s. 85-116.

Hejwowski K., Kognitywno-komunikacyjna teoria przekładu, Wydawnictwo Naukowe PWN, Warszawa 2004.

Lachman M., Menażeria stowa, „Didaskalia” 2012, nr 112, s. 166-168.

Romanowska A., „Hamlet” po polsku. Teatralność szekspirowskiego tekstu dramatycznego jako zagadnienie przekładoznawcze, Księgarnia Akademicka, Kraków 2005.

Subashi M., Ostrosi Veliaj E., Tennessee Williams's Dramatic World, „European Journal of Language and Literature Studies" 2015, vol. 1, no. 3, s. 76-81.

Totzeva S., Das theatrale Potential des dramatischen Textes. Ein Beitrag zur Theorie von Drama und Dramenübersetzung, Gunter Narr Verlag, Tübingen 1995.

Totzeva S., Realizing Theatrical Potential: The Dramatic Text in Performance and Translation, [w: The Practices of Literary Translation. Constraints and Creativity, red. J. Boase-Beier, M. Holman, St. Jerome Publishing, Manchester 1999, s. 81-90.

Williams T., A Streetcar Named Desire, The New American Library, New York 1974.

Williams T., Tramwaj zwany pożądaniem, przeł. E. Cękalski, „Dialog: miesięcznik Związku Literatów Polskich” 1957, R. 2, nr 6, s. 51-96.

Williams T., Tramwaj zwany pożądaniem i inne dramaty, przeł. J. Poniedziałek, Wydawnictwo Znak, Kraków 2012.

Windle K., The Translation of Drama, [w: ] The Oxford Handbook of Translation Studies, red. K. Malmkjær, K. Windle, Oxford University Press, Oxford 2011, s. 153-168.

Zatora A., Użycie konwencji. Instrumentarium grozy i jego misja $w$ "Ciemno, prawie noc” Joanny Bator, „Acta Humana” 2015, t. 6 (1), s. 211-225. 